\title{
Hunger Dependence of Electrical Brain Self-Stimulation in the Pigeon
}

\author{
JUAN D. DELIUS AND KIRSTI PELLANDER \\ Experimentelle Tierpsychologie, Psychologisches Institut, Ruhr Universität \\ Universitätsstraße 150, D-4630, Bochum-Querenburg, West Germany
}

\begin{abstract}
DELIUS, J. D. AND K. PELLANDER. Hunger dependence of electrical brain self-stimulation in the pigeon. PHYSIOL. BEHAV. 28(1) 63-66, 1982.-Contrary to recent evidence, further data showing that intracranial self-stimulation behaviour in the pigeon is frequently hunger-dependent is reported. A compilation of reinforcing brain loci in the pigeon suggests an association with two dopaminergic systems, the paleostriatal complex and the nucleus basalis system, the latter being known to be involved in the control of feeding.
\end{abstract}

Brain self-stimulation Hunger Pigeon

IN a recent study on reinforcing intracranial stimulation in the pigeon Zeigler et al. [15] failed to find any evidence for a hunger dependence of self-stimulation response rates. This result disagrees at least partially with previous findings of our own and others indicating that such a dependence was a salient characteristic of a high proportion of rewarding brain loci in the pigeon (see [2]). Zeigler et al.'s results also contrast with the widespread occurrence of hunger dependence of self-stimulation behaviour in mammals (see $[4,7])$. Here we report briefly some further results that bear on the issue in question and at the same time update a compilation of the anatomical location of self-stimulation sites in pigeon.

\section{METHOD AND RESULTS}

The methods were similar to those employed previously [2] and we shall only give a brief description here. Seven adult pigeons (Columba livia) of unknown sex were used. They were implanted stereotaxically under anaesthesia (Equithesin, intramuscular, $0.25 \mathrm{ml} / 100 \mathrm{~g}$ ) with a set of 4 staggered insulated stainless steel brain electrodes of 0.12 $\mathrm{mm}$ diameter with active surface tips between 0.2 and 0.3 $\mathrm{mm}^{2}$ surface. The electrodes were linked to a connector that was cemented to the skull. A loop of bare stainless steel wire under the scalp skin served as the indifferent electrode. After the behavioural experiments the animals were sacrificed and their brains processed for histology. The sections were examined under the microscope and the electrode-tip site locations were transferred to drawings taken from a pigeon brain atlas [5]. The sites are denominated with a three-cipher number where the two first ciphers identify the subject.

The subjects were food deprived to $80 \%$ of their normal weight and shaped to peck an illuminated key of a Skinnerbox for $3 \mathrm{sec}$ food access. When they responded steadily they were subjected to daily sessions consisting of three 10 min periods where they pecked either for food or for stimulation through one electrode $(0.5 \mathrm{sec}, 100 \mu \mathrm{A} \mathrm{rms}, 50 \mathrm{~Hz}$ sine waves) both on a continuous reinforcement schedule, or under extinction conditions, in randomized order. Each electrode was tested in 5 such sessions. An electrode was suspected to maintain self-stimulation if the number of responses during the stimulation periods was higher than during the extinction periods but also of the corresponding cumulative record showed a steadily ascending pattern as different from the progressively flattening curve typical of extinction. A presumed rewarding site was tested further in 4 daily sessions consisting of 4 randomized periods of $10 \mathrm{~min}$ in each of which the animals were reinforced with either 50 , 70,100 or $150 \mu \mathrm{A}$ stimulation currents. Of 21 sites tested as described above 7 proved to be reinforcing in that responding was maintained by the self-stimulation. They were henceforth stimulated at the current that had yielded maximal responding rates during the identification sessions.

Daily self-stimulation sessions lasting $20 \mathrm{~min}$ were now given as the subjects were gradually brought to full weight and ad lib feeding over 10 to 15 days and then again down to $80 \%$ to $75 \%$ weight over a similar period of time. The responses per session, in percent of the maximum number of responses obtained in any of these sessions, was plotted against the percent weight at the time of sessions. A correlation between the body-weight and the response score was found in 5 of the 6 sites tested (double median test, $\chi^{2}$, $p<0.01$ ). The correlograms corresponding to four sites are shown in Fig. 1, including the one site (302) that yielded no dependence. Sites 311 and 341 (not illustrated) produced dependences similar to those of loci 332 and 333. We note that site 354 may show an inverted U-shaped dependence with maximal responding at an intermediate level of deprivation. There is also some informal evidence that the deprivation dependence of this site, but not that of the other sites, may have progressively weakened though not disappeared during further experiments that took place in the two months following.

A further twelve 20 min sessions were conducted with the sites 341 and 354 while the subjects remained deprived at $80 \%$ weight. In 6 sessions the animals were tested after they 


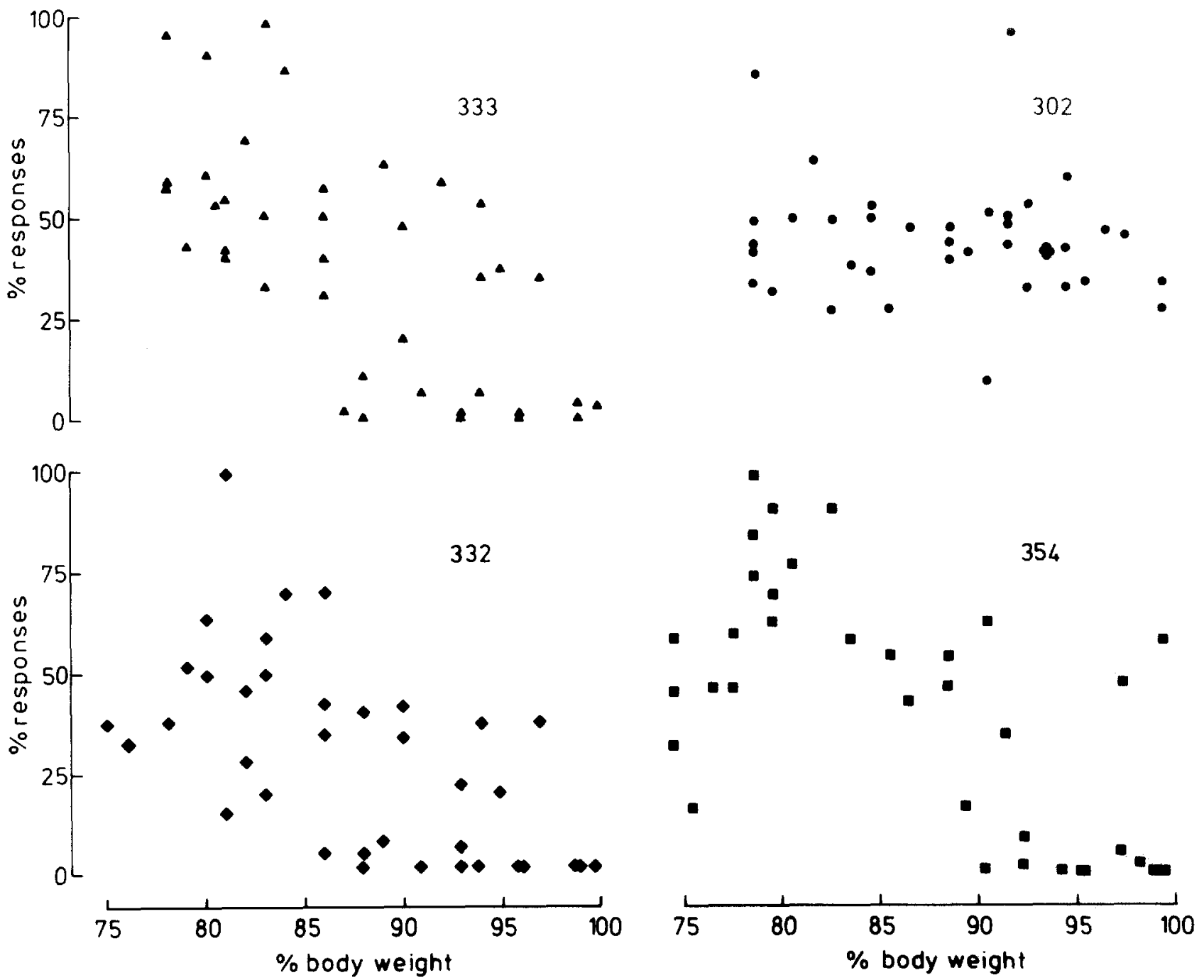

FIG. 1. Correlograms between self-stimulation response rates (in percent of maximum rate) and body-weight (in percent of normal weight) for four intracranial stimulation sites in the pigeon. Each point represents a 20 min session.

had access to $20 \mathrm{~g}$ food immediately before the sessions, this bringing their weight to about $87 \%$ of normal. The 6 sessions were alternated with 6 control sessions without such prefeeding. The results are shown in Table 1 which additionally shows the means of 8 similar sessions of 60 min duration. It is apparent the pre-sessions feeding, presumably leading to a short- term satiation, inhibited the self-stimulation behaviour in the brief sessions but that as the satiation dissipated in the extended sessions the inhibition disappeared.

With the same sites $(341,354)$ we made some attempts at establishing whether the stimulation might inhibit food intake, as one would expect under the hypothesis that their activation implicates the generation of satiation-like signals. The subjects deprived to $90 \%$ of their normal weight were given free access to food in 20 min sessions. In alternate sessions they were left undisturbed or brain-stimulated through the relevant sites with repeated $5 \mathrm{sec}$ trains, 6 per min, at various current settings. We found that for site 341 $40 \mu \mathrm{A}$ and for site $354,100 \mu \mathrm{A}$ stimulation would indeed
TABLE 1

MEAN RESPONSES PER 20 MIN IN SIX 20 MIN (SHORT) SESSIONS AND FOUR 60 MIN (LONG) SESSIONS AFTER HAVING BEEN PREVIOUSLY FED OR NOT

\begin{tabular}{ccccr}
\hline Electrode & Sessions & Not Fed & Significance & Pre-fed \\
\hline \multirow{2}{*}{341} & short & 240 & + & 64 \\
354 & long & 478 & - & 401 \\
& short & 296 & + & 83 \\
& long & 351 & - & 338 \\
\hline
\end{tabular}

The difference for the short sessions are significant (MannWhitney test, $p<0.01$ ). 

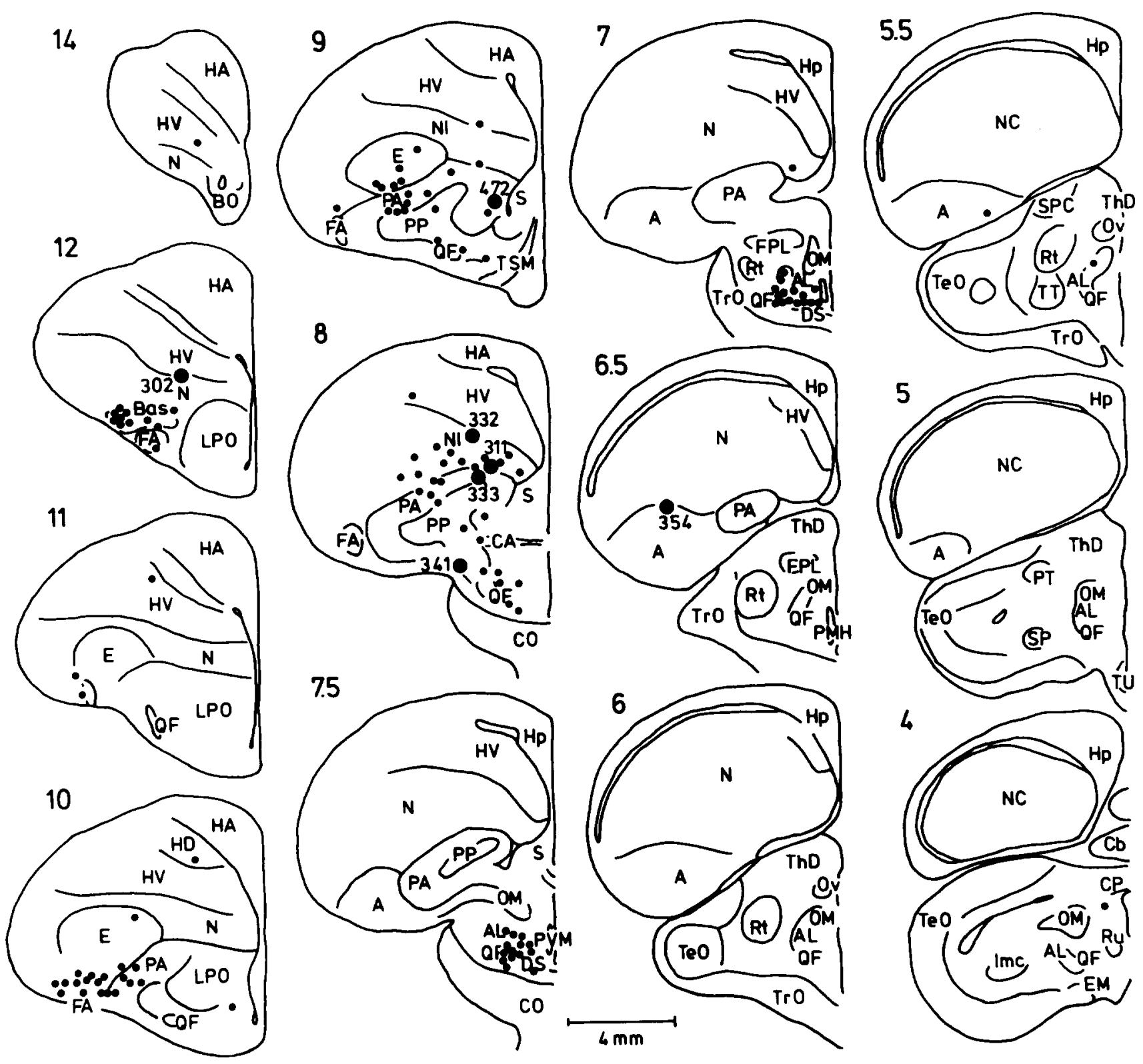

FIG. 2. Anatomical location of sites yielding self-stimulation in the pigeon, compiled from studies of our own and others (see text for details). The new sites of the present study are marked by larger circles and identified by their numbers. All sites have been plotted on the left side of the brain, irrespective of their actual location. The schematic transversal brain sections are derived from the Karten and Hodos atlas [5].

inhibit feeding reliably. However this was always associated with repeated head-shaking (341) or turning (354) that seemed to make feeding physically impossible. When currents were reduced so that stimulation did not elicit these incompatible responses the feeding inhibition disappeared or was uncertain. We add here that, as in our previous study, we could not find any correlation between the reinforcing properties of a site and the behaviour elicited through it by non-contingent, experimenter-controlled stimulation.

In a further test we assessed the effect of thirst upon the self-stimulation rate of 5 sites. Six 20 min sessions with the animals deprived of water for 36 hours alternated with six sessions with the animals fully satiated. Throughout this
TABLE 2

MEAN RESPONSES IN SIX 20 MIN SESSIONS ALTERNATELY UNDER 36 HRS WATER DEPRIVATION AND UNDEPRIVED

\begin{tabular}{ccc}
\hline Electrode & Deprived & Non-deprived \\
\hline 302 & 296 & 186 \\
311 & 4 & 11 \\
332 & 50 & 51 \\
333 & 21 & 8 \\
354 & 504 & 444 \\
\hline
\end{tabular}

None of the differences are significant. 
period the animals were fully fed. None of the sites showed a significant difference between the two conditions (Table 2 , Mann-Whitney tests, $p>0.05$ ). The slight non-significant increase in response in the deprived condition could be easily due to the secondary hunger that is well known to be induced by water deprivation [10]. It may be mentioned here that a separate search for thirst dependent self-stimulation sites in the pigeon has hitherto proved unsuccessful, 16 sites, vari ously located in the forebrain, having thus far been tested.

\section{DISCUSSION}

The present results confirm a frequent hunger dependence of self-stimulation in the pigeon although for some of the sites reported here it may have been less extreme than for those we studied earlier. We can not exclude that Zeigler et al.'s [15] discrepant results may have been due to differing locations of the stimulation sites. This however seems unlikely since some of his and our sites were quite similarly situated. It could also be that procedural differences are responsible. In the previous report we considered whether our results might be due to the particular method of identification we used, which included food-rewarded shaping of the instrumental response and initial self-stimulation under food deprivation. This could arguably have led to a kind of statedependent conditioning. Since however Zeigler et al . in most instances seem to have used a closely analogous procedure this hardly can explain the differing results. We believe that the hunger dependent self-stimulation is not a procedural artifact but a real and frequent phenomenon in the pigeon. Functionally it may be related to the fact that food is doubtlessly the most pervasive reinforcer in the free-ranging pigeon, but of course only when it is hungry. We may therefore expect to find a corresponding motivational gating phenomenon at the neural level. This has been discussed in more detail in our previous study.

The anatomical location of the present sites is shown in Fig. 2, along with a compilation of brain self-stimulation sites taken from [2], updated by including the positive loci reported in $[3,12,15]$. The new sites of this study fall well into place with the general distribution of the loci, sites 302 and
354 perhaps being slightly marginal. The overall pattern that emerges suggests a broad pathway that originates in the nucleus basalis and the neighbouring area, courses caudally along the tractus fronto-archistriaticus, swings medially at about the frontal level A 10 into the paleostriatum and overlying ectostriatum, spreads into the medial neostriatum intermedium more posteriorly and funnels through the paleostriatum primitivum into the lateral forebrain bundle and more specifically, through the ansa lenticularis.

This distribution pattern can be partially related to known connections of the avian paleostriatal complex $[1,6]$ and the nucleus basalis system [14]. The link-up between the two networks however is uncertain. We should note that, apart from those sites that are obviously associated with basalis system structures, sites along the ansa lenticularis could be effective through the tractus quinto-frontalis that runs close to it through the diencephalon. The involvement of the nucleus basalis system is of particular interest in the present context because it has been implicated in the control of feeding ([14], but see [9]). A homologization of the substrates with the mammalian self-stimulation system still seems fraught with difficulties and will not be attempted here except by remarking that the paleostriatal complex appears to be homologous to the basal ganglia but that the nucleus basalis system does not seem to have an obvious mammalian equivalent $[1,14]$. We note that the septum of birds, quite differently from the septum in mammals [13] does not seem to support self-stimulation.

In conjunction with the much mooted association between catecholaminergic systems and self-stimulation in mammals [13] we note that the paleostriatum augmentatum is rich in dopamine $[6,8]$. The nucleus basalis and tractus fronto-archistriaticus also appears to contain dopamine [11].

\section{ACKNOWLEDGEMENTS}

The work was partially supported by the Deutsche Forschungsgemeinschaft through its Sonderforschungsbereich 114. We thank Dr. J. Emmerton, D. Hagenkötter, A. Lohmann, P. Zierow and H. Stankewitz for assistance.

\section{REFERENCES}

1. Brauth, S. E., J. L. Ferguson and C. A. Kitt. Prosencephalic pathways related to the paleostriatum of the pigeon. Brain Res. 147: 205-221, 1978.

2. Delius, J. D., A. S. Williams and R. J. Wooton. Motivation dependence of brain self-stimulation in the pigeon. Behav. Proc. 1: $15-27,1976$

3. Goodman, I. J. Approach and avoidance effects of central stimulation: an exploration of the pigeon fore- and mid-brain. Psychon. Sci. 19: 39-41, 1970.

4. Hoebel, B. G. Brain stimulation reward and aversion in relation to behaviour. In: Brain-stimulation Reward, edited by A. Wauquier and E. T. Rolls. Amsterdam: North Holland, 1976, pp. 336-372.

5. Karten, H. J. and W. A. Hodos. A Stereotaxic Atlas of the Brain of the Pigeon. Baltimore: Johns Hopkins Press, 1967.

6. Karten, H. J. and J. L. Dubbeldam. The organization and projections of the paleostriatal complex in the pigeon. J. comp. Neurol. 148: 61-90, 1973.
7. Katz, R. J., G. Baldrighi and K. Roth. Appetitive determinants of self-stimulation. Behav. Biol. 23: 500-508, 1978.

8. Kusonaki, T. The chemoarchitectonics of the avian brain. $J$. Hirnforsch. 11: 477-497, 1970.

9. Martin Ramirez, J. Forebrain lesions and food intake in pigeons. Physiol. Behav. 23: 981-984, 1979.

10. McFarland, D. J. Interaction of hunger and thirst in the Barbary dove. J. comp. physiol. Psychol. 58: 174-179, 1964.

11. Minelli, G. Ricerche istochimiche dell' encefalo di Testudo graeca e Coturnix coturnix. Riv. Biol. 63: 61-86, 1970.

12. Simmerman, S. J. Response-contingent intracranial self-stimu lation of the pigeon diencephalon. Ph. D. Thesis, University of North Carolina, Chapel Hill, 1976.

13. Wauquier, A. and E. T. Rolls. Brain-Stimulation Reward. Amsterdam: North Holland, 1976.

14. Zeigler, H. P. Feeding in the pigeon. Adv. Stud. Behav. 7: 285389,1976

15. Zeigler, H. P., V. D. Hollard, J. M. Wild and D. M. Webster Intracranial self-stimulation from endbrain nuclei in the pigeon. Physiol. Behav. 21: 387-394, 1978. 